\title{
Uluslararası Güvenliğe Giriş
}

\section{Ayça EMINOĞLU ve Murat ÜLGÜL (Editörler)}

Ankara, Nobel Yayınları, 2021, 486 sayfa

Introduction to International Security

\section{Anıl Çağlar ERKAN ${ }^{*}$}

Geliş Tarihi/Received: 02.09.2021

Kabul Tarihi/Accepted: 14.09.2021

Kitap İncelemesi/ Book Review

Uluslararası ilişkiler disiplini Türkiye'de gelişim sürecindeki en popüler alanların başında gelmektedir. Her geçen gün gelişen literatürü bunun göstergelerindendir. Şubat 2021 tarihinde Nobel Yayın Grubu tarafından okurların beğenisine sunulan editörlüklerini değerli bilim insanları Ayça Eminoğlu ve Murat Ülgül'ün üstlendiği "Uluslararası Güvenliğe Giriş" kitabı uluslararası ilişkilerin gelişen literatürüne en değerli katkıyı yapan eserlerden birisi olarak karşımıza çıkmaktadır. Yoğun bir süreç sonrasında okuyucuların beğenisine sunulduğu ilk bakışta göze çarpan eser, on altı değerli bilim insanının kaleminden on dört ayrı bölümden oluşmaktadır. Bununla birlikte eserin Prof. Dr. Sinem Akgül Açıkmeşe'nin önsözüyle basıldığını da belirtmek de fayda görülmektedir. İçerik bağlamında ele alındığında, ilk bölümü Çiğdem Üstün ve Bezen Balamir Coşkun'un ‘Uluslararası Güvenlik: Kavramlar ve Teorik Yaklaşımlar" başlıklı çalışmaları teşkil etmektedir. Bu bölümde Üstün ve Coşkun, ilk olarak uluslararası sistemde güvenlik anlayışımızın değişkenliğine yani dinamik niteliğine vurgu yapmaktadırlar. Bu bağlamda teorilerin gelişimini, ihtiyaçların karşılanmasıyla ilişkilendirirken kavramsal olarak gelișimin varlığını ifade etmektedirler. Amaç bakımından ele alındığında bölümde, değişen uluslararası güvenlik anlayışı ele alınırken, bölgesel düzlemden global düzleme güvenlik nosyonunun algılardaki karşılığı ve bununla ilişkili konuları ele alırken tercih

\footnotetext{
${ }^{1}$ Öğr. Gör., Burdur Mehmet Akif Ersoy Üniversitesi, Tefenni Meslek Yüksekokulu, Yönetim ve Organizasyon Bölümü, Orcid No: 0000-0001-9693-6556

* Sorumlu yazar/Corresponding author

E-mail/e-ileti: acerkan@mehmetakif.edu.tr
} 
ettiğimiz teorik çerçevenin özetini sunulması hedeflenmektedir. Dolayısıyla bu bölümde öncelikle güvenlik, kavramsal olarak ele alınmış ve bunun uluslararası güvenlikle bağlantısı kurularak anlaşılanlar gün yüzüne çıkarılmıştır. Fakat bu süreçte konseptin daha öncede vurgulanan dinamizmi görmezden gelinmemiştir. Daha açık bir deyişle Üstün ve Coşkun çalışmalarında uluslararası güvenlik kavramının zaman içerisinde gösterdiği değişimle birlikte bölgesel ve uluslararası güvenlik arasındaki ilişkiyi de ele almaktadırlar. Bunun sonrasında yazarlar, uluslararası güvenlik konusunu analiz eden gerçekçi, liberal ve sosyal inşacı gibi uluslararası ilişkiler disiplininin temelinde kendine yer edinen ana akım teoriler ile güvenlikleştirme ve eleştirel teorilerin güvenlik kavramına yaklaşımlarını özetlemektedirler.

Çalışmanın ikinci bölümünde güvenlik çalışmalarının en önemli saç ayaklarından birisini oluşturan ekonomik güvenlik konusu, Selim Kurt tarafından "Ekonomik Güvenlik: Kavramsal ve Teorik Bir Analiz” başlığı altında ele alınmaktadır. Çalışmasında Kurt öncelikle uluslararası ilişkiler alanında güvenliğin klasik gündeminin odaklandığı konulara vurgu yapmakta ve bu konuların dahil özlerinde yaşanan değişimler ve politik, ekonomik, toplumsal ve çevresel faktörlerden kaynaklanan başka tehditlerin de güvenliğin gündemine dahil edilmesi zorunluluğunu doğurduğunu ifade etmektedir. Soğuk Savaş döneminin geride kalması ise söz konusu değişimle ilişkili olarak dönüm noktası niteliğindedir. Çünkü Kurt'a göre, “Soğuk Savaş'ın sona ermesi, devletlerin askeri meselelerden çok ekonomiye daha önem vermesini de beraberinde getirmiştir. Dolayısıyla bu alandan kaynaklanan tehditleri daha da ciddiyetle ele almalarına sebebiyet vermiştir. $\mathrm{Bu}$ ise, ekonomik güvenlik meselelerine yönelik ilgiyi arttırarak, güvenlik alanında askeri faktörlerin yanı sıra ekonomik faktörlerin de belirginleşmeye başlamasına yol açmıştır” (Kurt, 2021: 39-40). Bu bağlamda Selim Kurt, küresel yapının temel aktörleri olarak devletlerin kabulü ve uluslararası ilişkilerin devletler arasındaki ilişkilere odaklanması dolayısıyla bu çalışmasında ekonomik güvenlik kavramını makro bir bakış açısıyla küresel seviyede incelemektedir. Bununla birlikte teorik açıdan ekonomik güvenlik kavramı ele alınmış ve çalışmada üç temel ekonomi-politik teori olan merkantilizm, liberalizm ve yapısalcılık çerçevesinde konseptten ne anlaşılması gerektiği açık olarak ortaya konmuştur. Ayrıca çalışmada ekonomik güvenlik kavramının ne şekilde evirildiğinin ele alınması dikkat çekicidir.

“Uluslararası Güvenliğe Giriş” kitabının üçüncü bölümünde son dönemde teknoloji ve enformasyon alanlarındaki "devrim” olarak nitelendirebileceğimiz gelişmelerle ilişskili olarak nispeten "yeni”" olarak nitelendirebileceğimiz tehdit konularından birisi ele alınmaktadır. Bu bağlamda Salih Bıçakçı’nın “Siber Güvenlik ve Savunma” başlıklı çalışmasının söz konusu 


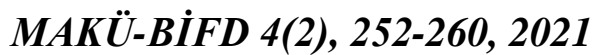

yeni tehditlere ilişkin meseleleri en azından tanıma ve anlamlandırma bakımından yol gösterici olacağını ifade etmek mümkündür. Bununla ilişkili olarak Bıçakçı'nın öncelikle Bacon'dan alıntı yaparak bilgi ve güç arasındaki ilişkiye vurgu yapması ve Foucault tarafından söz konusu bağlantının tekrar altının çizildiğini ifade etmesi, çalışmanın önemi açısından iyi bir çerçeve sunmaktadır. Bununla birlikte çalışmada nispeten yeni olarak nitelendirebileceğimiz kavramlara yer verilmekte ve siber ortamın tarihsel gelişim süreci kısaca özetlenmektedir. Hemen hemen her bireyin hayatında kilit önemdeki siber alan ve ilişkili olguların, terimsel karşılıkları ve kavramların açıklanmasının literatür ölçeğinde akademik zemine dayandırılması ise çalışmanın nitelik ve niteliğine pozitif yönlü katkı sağlamaktadır. Bu bağlamda dijital verilerin karşı kaşıya olduğu güvenlik tehditleri daha anlaşılır bir hale gelmiştir.

Çalışmada ses getireceği düşünülen en özgün bölümlerin başında şüphesiz Prof. Dr. Gökhan KOÇER tarafından kaleme alınan "Pandemiler ve Küresel Güvenlik Ezeli ve Ebedi Tehdit: Dördüncü Atlı" başlıklı çalışması yer almaktadır. Koçer'in çalışması daha "Giriş: Kadim Tehdit" başlığından itibaren okuyucuya etkili ve akııı bir şekilde "karmaşık ve muğlak" bir güvenlik meselesini anlaşılır hale getirmektedir. Bu bağlamda Koçer'in ifadelerinin bir bakıma anlaşılması zor ve karmaşık bir dili, adeta açık ve anlaşı1ır bir hale getiren niteliği olduğu iddia edilebilirdir. Öyle ki çalışmanın daha ilk satırlarındaki Vahiy kitabına yapılan “Mahşerin Dört Atlısı” alıntısı cidden çarpıcıdır. Bununla birlikte kitaptaki “dördüncü atlının” özellikle 2020 itibariyle insanlığın karşısında tekrar çıkan ve göz ardı edilmemesi gerekliliğini acı bir şekilde bizlere gösteren Covid-19 salgınıyla ilişkilendirilmesi çalışmadaki en önemli tespitlerdendir. Dolayısıyla Koçer çalışmasında, bu ve benzeri hastalıkların en kadim tehdit unsuru olduğunu ve tarih boyunca insanlık için en büyük tehdidi oluşturduğunu, yaşanan gerçeklerle sabitlenmiş niteliğine vurgu yapmaktadır. Ayrıca Koçer, dünya tarihinde yarattıkları etkiye karşın, bulaşıcı ve salgın hastalıklara Uluslararası İlişkiler disiplininde ve uluslararası güvenlik alanında yeterince yer verilmediğini ifade etmektedir. $\mathrm{Bu}$ noktadan hareketle Koçer'in çalışması, alanda yeterince kendisine yer verilmeyen salgın ve bulaşıcı hastalıklar konusunu uluslararası ilişkiler ve uluslararası güvenlik bağlamında ele alınan bir deneme olarak karşımıza çıkmaktadır.

Uluslararası güvenliğin olmazsa olmaz konularından biri haline gelen tehditler arasında gösterilen “Enerji Güvenliği”, Vahit Güntay tarafından kitapta ele alınmaktadır. Güntay’a göre "Bir kavramdan daha çok bir alanın tekrar düşünülmesini sağlayan gelişmeler enerji güvenliği konseptinin ya da başlı başına çalışma aritmetiğinin tarihini yeniden yazdırmaya başlamıştır" (Güntay, 2021: 127). Çalışmanın bu bölümünde değişen dengeler ve enerjiye artan bağımlılığa pek çok politik tartışmanın da merkezinde yer almaya başlayan bir faktör olarak yer 


\section{Erkan, $A$. Ç.}

verilmektedir. Dolayısıyla enerji güvenliği kavramı artık esneklikle eş anlamlı hale gelmektedir ve sorunlara hızlı bir şekilde reaksiyon gösterebilmek için, iç ve dış politikada stratejiler inşa edebilmek hemen hemen her devletin güvenlik ajandasında yer alan bir enerji sorunsalını da beraberinde getirmektedir. Bu ise böyle bir sorunsal karşısında hızlı kararların alınması için çok yönlü bir analiz ihtiyacını ve zorunluluğunu ortaya çıkarmaktadır. Tüm bunlar ışığında Güntay çalışması dahilinde, artan önemi ve mücadele alanı olması itibariyle enerji güvenliği konseptini kavramsal olarak incelemektedir. Çalışmada enerji güvenliğinin uluslararası güvenlik içerisindeki konumuna yoğunlaşılması çalışmaya son derece özgün bir değer kazandırmaktadır. Ayrıca çalışmada enerji güvenliği konseptinin teori ve pratikte açıklayıcı bir şekilde karşılaştırmalı olarak tartışılması literatüre önemli bir katkı olarak karşımıza çıkmaktadır.

Çalışmanın altıncı bölümünde literatürde çok sayıda çalışmaya konu olsa da içerik bağlamında halen daha muğlak yönlerinin varlığı tartışmasız güvenliğin insani yönü ele alınmaktadır. Bu minvalde Kristin Vandenbelt'in "İnsani Güvenlik” başlıklı çalışmasına Murat Ülgül tarafından dilimize çevrilerek kitap içeriğinde ayrı bir bölüm olarak yer verilmektedir. Çalışmanın giriş bölümünde öncelikle 1991 yılı sonunda Sovyetler Birliği’nin dağılmasıyla birlikte iki kutuplu göreceli istikrarlı bir dünya düzeninin yok olduğu ve yıkılanlar arasında politik düzeyde dünyanın işleyişine dair anlayışımızın da yer aldığı ifade edilmektedir. Politik düzeydeki bu y1kım ise Vandenbelt'e göre "kaos" olarak nitelendirilmektedir. Öyle ki Vandenbelt' in "Ortaya çıkan uluslararası kaos akademisyenleri, araştırmacıları ve siyasetyapıcılarını gelişen dünya düzenini anlamak ve açıklamak için yeni konseptler aramaya itmiştir” şeklindeki ifadeleri bunun göstergelerindendir (Vandenbelt, 2021: 161). Bu bağlamda insani güvenlik kavramı merkeze alınmaya başlayan bir süreç içerisine girmiştir. Hatta insani güvenlik kavramının "bir tür moda sözcük” haline gelmeye başladığı bile ifade edilmektedir. Tüm bunlar ışığında çalışmanın bu bölümünde insani güvenlik kavramına yönelik yeni teorik yaklaşımları incelemenin yanında kavramın kendisinin de derinden bir analizi yapılmaktadır. Bu doğrultuda insani güvenlik kavramının tarihi ve anlamı doğrultusunda yapılan analiz önemli bir başlangıç olarak karşımıza çıkmaktadır. Bu kapsamda çalışmada 1994 yılından bu yana konseptin kullanımı ve süreç ele alınmaktadır. Devamında ise insani güvenliğin karşılaştığı değerlendirmeler ve muhalif olarak da nitelendirebileceğimiz eleştiri ve kritikler incelenmiştir. Çalışmanın son bölümünde ise akademik ve politik seviyede insani güvenlik kavramının geleceğine yönelik bakışla konseptin yol haritası belirlenmiştir.

Uluslararası Güvenliğe Giriş kitabının yedinci bölümünde etnik çatışma konusu editörlerden birisi olan Murat Ülgül tarafından ele alınmaktadır. Çalışmanın bu bölümünün 


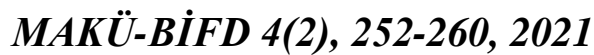

başlığı ise "Etnik Çatışma" olarak karşımıza çıkmaktadır. Etnik çalışma literatürünün önemli isimlerinin ifadelerine yer veren Ülgül'ün bu kapsamda Stuart J. Kaufman'ın "Modern Nefretlerl başlıklı çalışmasına yapmış olduğu atıflar özellikle dikkat çekmektedir. Öyle ki Ülgül çalışmasının giriş kısmında Kaufman'ın söz konusu eseriyle ilişkili olarak “milliyetçiliğin yedi kuralı" adıyla etnik politika ile ilgilenenler için bir "başlangıç rehberi”" sunarak başladığının altını çizmektedir (Ülgül, 2021: 197). Bu doğrultuda Ülgül çalışmasına Kaufman'ın "ironi” içeren rehberiyle başlamasının okuyucuda çalışmanın içeriğinin daha anlaşılır olacağı öngörüsünü uyandırdığını ifade etmek mümkündür. Ülgül'ün çalışmasının bu bölümünde etnik çatışma ile ilgili literatürü üç aşamada ele alarak incelediği görülmektedir. $\mathrm{Bu}$ bağlamda ilk olarak etnik çatışmanın kavramsallaştırılmasıyla ilgili karşılaşılan sorunsal incelenmekle birlikte, ayrıca etnik kimliğin orijini ile ilgili olarak farklı perspektifler ele alınmaktadır. Çalışmanın ikinci kısmında ise etnik çatışmaların altında yatan dinamiğine ilişkin soru işaretlerine açıklık getirilmektedir. Ayrıca konu ile ilişkili soruları yanıtlayan teorilerin sınıflandırıldığına tanıklık edilmektedir. Dolayısıyla çalışmanın özgün değeriyle birlikte literatüre yapmış olduğu katkı bu noktada ortaya çıkmaktadır. Çalışmanın son kısmında çözüme yönelik perspektiflere yer verilmektedir. Daha açık bir deyişle çalışmanın üçüncü ve son kısmında etnik çatışmaların nasıl çözüleceğine yönelik farklı teorik yaklaşımlar incelenmektedir.

Eminoğlu ve Ülgül'ün editörlüklerini üstlendikleri kitabın sekizinci bölümünde canlı yaşamının sürdürülebilirliğinin olmazsa olmazı çevreye ilişkin tehditler ele alınmaktadır. Bir bakıma yaşam sahamızı ciddi tehdit eden bu meseleler, Ceren Uysal Oğuz ve Senem Atvur tarafından "Çevresel Güvenlik" başlığı altında ele alınmaktadır. Uysal Oğuz ve Atvur çalışmalarında çevre konusunun uluslararası politikanın gündemine girmesine neden olmuş olan gelişmelere değinerek analizlerine ilişkin tarihsel süreci kısaca özetlemişlerdir. $\mathrm{Bu}$ bağlamda 1972 yılında Birleşmiş Milletler (BM) çatısı altında düzenlenen ve Stockholm Konferansı olarak bilinen "İnsan Çevresi Konferansı" bu yönde atılan ilk adım olarak ifade edilmektedir. Ayrıca yazarlar, ekosistemlerin karmaşık karşılıklı bağımlılığı ile sınır aşan etkiler doğuran ekolojik sorunlar, Soğuk Savaş'ın son yıllarından itibaren Uluslararası İlişkiler disiplini içinde farklı bağlamlarda çalışılmaya başlandığını dile getirmektedirler. Ancak Uysal Oğuz ve Atvur'un söz konusu çalışılmaya başlananlar arasında güvenlik-çevre ilişkisine ayrı bir önem atfettiklerine tanıklık edilmektedir. Tüm bunlar 1şığında çalışmanın bu bölümünde yazarlar, güvenlik çalışmalarının içinde çevre başlığının neden yer bulmaya başladığı, çevresel güvenliğin ne olduğu, ekolojik sorunlar ve güvenlik ilişkisine alternatif bakış açılarının neden 


\section{Erkan, $A$. Ç.}

ortaya çıktığı ve çevresel güvenliğin diğer güvenlik sorunlarıyla nasıl kesiştiğini ele almaktadırlar.

Uluslararası İlişkiler disiplini ve literatüre önemli katkı sağlaması kaçınılmaz olan kitabın dokuzuncu bölümünde nükleer güvenlik meselesi Murat Ülgül tarafindan ele alınmaktadır. Çalışmada Ülgül'ün nükleer güvenlik meselesini farklı bakış açısıyla, yani etnik çatışma ve uluslararası güvenliği tehdit ettiği konusunda özellikle batı literatürünün ortak paydada olduğu "cihatçı" oluşumları da içerisine alan terör gruplarını da dahil ederek ele alınması, konunun devletler arası olmanın ötesin e taşıması açısından son derece önemlidir. $\mathrm{Bu}$ bağlamda öncelikle nükleer silahlar ve güvenlik ikilemi etkileriyle birlikte ele alınmaktadır. Uluslararası toplumun oynamış olduğu role de bu kapsamda yer verilmekte ve nükleer silahların yıkıcı etkisiyle birlikte çekiciliği incelenmektedir. Temel olarak bakıldığında bu bölümde neden devletlerin nükleer silaha sahip olmak istediği, nükleer silahlanmaya karşı ne gibi politikalar takip edebileceği ve Soğuk Savaş sonrası dönemde "ikinci nükleer çă̆g" olarak nitelendirilen bir zamanda önemi artan nükleer terörizm tehlikesi analiz edilmektedir.

Uluslararası Güvenliğe Giriş kitabının onuncu bölümünün başlığı "Uzay Güvenliği”" olarak karşımıza çıkmaktadır. Söz konusu başlık altında çok nadir olarak karşılaştığımız çalışma sahalarından uzay güvenliği konsepti Mehmet Emin Erendor tarafından ele alınmaktadır. Gelişen teknolojiyle birlikte yeniden gündeme gelmiş olan uzay merkezli ya da tabanlı çalışma alanına yer verilmesini başta ilgili bölüm olmak üzere bu kitabın akademik literatüre önemli bir katkısı olarak nitelendirmek mümkündür. Literatür açısından olumlu katkıları tartışmasız olan bu bölümde temel olarak uzay güvenliği detaylı bir şekilde incelenmiştir. $\mathrm{Bu}$ çerçevede uzay konseptinin epistemolojik yapısı analiz edilerek uzayın kapsamı, kavramsal karşılığı ve ilişkili yapılan çalışmalara yer verilmektedir. Ancak uzay güvenliğine yönelik faaliyetlerin detaylandırıldığına ve bu kapsamdaki silahsızlandırılma konusuna ayrıntılı bir şekilde odaklanıldığının altını çizmek gerekmektedir. Çalışmada ayrıca uzay güvenliğine yönelik uluslararası sistemde oluşturulma çabası içerisinde olan anlaşmalar, sözleşmeler ve teşebbüslere yer verilerek, sistemin temel aktörleri devletlerin uzayın hukuki statüsüne ilişkin perspektifleri irdelenmektedir.

Eminoğlu ve Kalyoncu'nun “Kopenhag Okulu ve Güvenlikleştirme Teorisi” başlıklı çalışmaları kitabın on birinci bölümünü teşkil etmektedir. Eminoğlu ve Kalyoncu çalışmalarında öncelikle Kopenhag Okulu'yla ilişkili tarihsel sürece değinerek, çalışmanın kavramsal çerçevesini çizmektedirler. Bununla ilişkili olarak yazarlar 1985'ten itibaren okulun, Avrupa'nın güvenliği üzerine yoğunlaştığını, askeri olmayan ve tehdit unsuru olarak 


\section{$M A K \ddot{U}$-BIFD 4(2), 252-260, 2021}

değerlendirilmeyen konular üzerinden güvenlik incelemeleri yaptığına vurgu yapmaktadırlar. Dolayısıyla Kopenhag okulu güvenliğin dar çerçevesini temsil eden askeri tehditlerin yanında, daha evvel risk teşkil etmeyen ve geniş çerçeve olarak ifade edilen sağlık, ekonomi, siyasi ve sosyal meseleler, terör ve göç gibi konuları da çalışmalarının odağına yerleştirmiş olarak karşımıza çıkmaktadır. Kopenhag ekolünün ele alınması ise literatüre katkısı ise güvenlik çalışmalarına farklı bir yaklaşım getirmesi olarak bu bölümde ifade edilmektedir. Eminoğlu ve Kalyoncu'ya göre ekolün literatüre yapmış olduğu en önemli katkı ise güvenlik yaklaşımını yansıtan politikası güvenlikleştirme kuramıdır. Güvenlikleştirme kuramına çalışmanın odağında yer verilmesi bunun göstergelerindendir. Bu bağlamda Eminoğlu ve Kalyoncu ilk aşamada güvenlik konseptine kavramsal çerçevede değinmişler ve farklı perspektiflerden konuyu irdelemişlerdir. Bu aşamada tarihsel sürecin ele alınması konsept ile ilişkili gelişmeleri daha anlaşılır bir temele dayandırılmasına olumlu katkı yapmaktadır. Sonraki aşamada Kopenhag Okulu'nun uluslararası toplum merkezli görüşünü yansıtan realist eleştirilerine yer verilmiş ve ekolün başta Buzan gibi düşünürlerce güvenlik kavramını çeşitli parçalara ayrıştırarak sektörel temelde incelenmesi gerektiğinin savunulması ile ilişkili savlara yer verilmiştir. Çalışmanın sonraki bölümünün kavramsal çerçeveyle birlikte teorik yaklaşımları pratikte güncel gelişmelerle harmanlaması ve politik refleks alt başlığg örneğindeki gibi aktörün tehdidi nasıl bertaraf edeceğine ilişkin sorunsala uzanan güvenlik kavramının saç ayaklarına yer verilmektedir.

Uluslararası Güvenliğe Giriş kitabının on ikinci bölümünde Bülent Şener'in "D1ş Politikada Kriz Yönetimi ve Bir Kriz Yönetimi Stratejisi Olarak Zorlayıcı Diplomasi” başlıklı çalışmasına yer ver verilmektedir. Çalışmanın bu bölümü öncelikle uluslararası ilişkiler disiplinini ve politikanın hemen hemen her aşamasında karşılaşılan ve literatürün ağırlıklı uğraşısı haline gelen uluslararası politika disiplininin bir alt dalı haline gelecek kadar önemli bir alana ilişkin Dış Politika Analizine odaklanması bağlamında akademik değeri olduğunu ifade etmek mümkündür. Dolayısıyla kitabın bu bölümü son derece değerli bir konuyu ele alması nedeniyle literatüre önemli katkı yapacak potansiyeldedir. Bununla birlikte dış politika analizinin kriz kavramı ve yönetim süreçleriyle ilişkili olarak ele alınması bu bölümün yapmış olduğu katkılar kapsamında değerlendirilebilmektedir. Çalışma kapsamında, kavramsal çerçevenin giriş başlığında açık ve anlaşılır bir şekilde ele alınmaktadır. Daha sonraki başlık altında söz konusu kavramsal çerçeveye ilişkin ele alınan konu kapsamında dış politikada karar alma süreci ve karar alma modellerine değinilmiştir. Kriz olgusu ve kavramının etimolojik ve semantik açıdan ele alınması ise kavramsal çerçevenin bir diğer boyutu olarak karşımıza çıkmaktadır. Kavramsal çerçevenin çizilmesiyle birlikte çalışmada dış politika analizi, kriz 


\section{Erkan, $A$. Ç.}

süreci, evre ve stratejileriyle birlikte ayrıntılı olarak analiz edilerek zorlayıcı diplomasiyle ilişkilendirilmiş ve irdelenmiştir.

Uluslararası güvenlik konseptiyle ilişkili olarak karşımıza çıkan en güncel tarihli yayınlardan birisi olan Uluslararası Güvenliğe Giriş kitabının on üçüncü bölümünde Sanem Özer'in “Göç ve Uluslararası Güvenlik” başlıklı çalışmasına yer verilmektedir. Sanem Özer bu çalışmada göç ve güvenliği genişleyen ve iç içe geçen boyutlarıyla incelemektedir. Özer'e göre "Nasıl ki göç kaynakları, dinamikleri ve sonuçları iler küresel bir olgudur, ulusal güvenlik de küresel bir hal almıştır" (Özer, 2021: 416). Bu bağlamda uluslararası ya da başka bir deyişle küresel güvenliğin, hiçbir ulusal güvenlik aygıtı küreselleşmenin devlete yönelttiği talepleri tek başına yönetemeyeceği için devletlerin iş birliği yapmak zorunluluğu duyması göze alındığında, bu durum küresel bağlantı ve karşılıklı bağımlılık gibi faktörleri karşımıza çıkarmaktadır. Bununla bağlantılı olarak çalışmasında Özer, küresel bağlantı ve karşılıklı bağımlılığın devletlerin daha fazla iş birliği yapmasını ve birlikte çalışmasını gerekli kıldığını ifade etmektedir. Konu ile ilişkili olarak da devletlerin çok yakın zamana kadar göçü sınır yönetimi aracılığıyla denetlenebilir ve ulusal bir mesele olarak gördüklerinin altını çizmektedir. Çalışmanın ana teması ise bu noktada ortaya çıkmaktadır. Öyle ki devletlerin yaklaşımına karşın göçü yönetmenin sanıldığı kadar her daim kolay olmadığı çalışmada özellikle ortaya konmaktadır. Bu durum tamamen göçün dinamikleriyle ilişkilendirilmektedir. Tüm bunlar 1şığında çalışmasında Özer, ilk olarak göç ve güvenliği genişleyen ve iç içe geçen kavramlar olarak ele almaktadır. Bunun sonrasında çalışmanın ikinci bölümünde uluslararası ilişkiler teorilerinin özellikle zorunlu göçe yaklaşımlarına yer verilmektedir. Güvenlikleştirme ve insani güvenlik gibi temalarla ele alınan göç meselesiyle ilişkili olarak küreselleşme ve artan mobilite birlikte yeni güvenlik tehditleri ele alınmaktadır.

Kitabın son bölümünde Mete Ulaş AKSOY'un 'Uluslararası İlişkiler Teorilerinde Eleştirel Güvenlik Yaklaşımları” başlıklı çalışmasına yer verilmektedir. Çalışmada öncelikle eleştirel güvenlik yaklaşımlarının ortaya çıkışı ve gelişimine değinilerek kavramsal çerçevenin zemini oluşturulmuştur. Söz konusu yaklaşımların özgün niteliklerine de bu aşamada değinilmiştir. İçerik bağlamında Aksoy’un çalışmasında eleştirel güvenlik yaklaşımlarının genel bir incelemesi ve değerlendirilmesinin yapıldığı görülmektedir. Bu doğrultuda Aksoy ilk olarak güvenliğe yönelik eleştirel teorik tutumların orijinine ilişkin düşünsel bağlamın anlaşılabilmesi adına, uluslararası ilişkiler teorisine dair genel bir tablo çizmekte ve bu tabloda güvenliğin ele alınmasının niteliksel olarak ortaya koymaktadır. Daha sonraki bölümde ana akım yaklaşımlara ilişkin eleştirel paradigmanın güvenlik anlayışının meydan okuduğu bağlam 
MAKÜ-BIFD 4(2), 252-260, 2021

ve koşullara yer verilmiştir. Bu aşamada spesifik olarak iki eleştirel güvenlik okuması üzerinde durulduğu göze çarpmaktadır. Bunlar ise eleştirel güvenlik çalışmaları ve post-yapısalcı yaklaşımlar olarak karşımıza çıkmaktadır. Çalışmayı değerli hale getiren dinamik ise sonuç bölümünde eleştirel yaklaşımlar için alternatif bir perspektif gündeme getirmesidir.

Sonuç olarak 2021 yılında Nobel Yayınevi tarafından okuyucuların beğenisine sunulan Uluslararası Güvenliğe Giriş kitabı şüphesiz Eminoğlu ve Ülgül'ün editörlükleri ve katkısı bulunan yazarların çalışmalarıyla bir bütün olarak literatüre ciddi ölçekte olumlu katkı yapacak temel başvuru kaynakları arasında yer alacak potansiyeldedir. Zaman içerisinde bu çalışmanın gerek uluslararası ilişkiler lisans ve lisans üstü gerekse alanla yakından ilgilenenler için temel bir kılavuz ya da başucu kaynak haline dönüşebileceği tartışmasızdır. Uluslararası güvenlikle ilişkili olarak güncel meselelere yer vermesi kitaba ilişkin nitelik ve potansiyelin en önemli nedenlerindendir. Bununla birlikte konuların sadece teorik perspektiften ele alınmaması ve pratik bağlamında son dönemde karşılaşılan güncel hadiselerle harmanlanarak karmaşıklıkların daha anlaşılır hale getirilmesinin de katkısı büyüktür. Dolayısıyla büyük emeklerin bir yansıması olarak karşımıza çıkan bu eserin, uluslararası ilişkiler disiplini literatürünün ağırlığını taşıyacak özgünlük ve dinamizme sahip olduğu iddia edilebilirdir. 